\title{
"Y volver, volver, volver": Reescritura picaresca y mundos posibles en Para morir iguales de Rafael Reig
}

Recibido: 16/12/2019. Aceptado: 2/10/2020.

\begin{abstract}
Resumen
Contraviniendo el mito del pícaro estudiado por Claudio Guillén, el narrador asturiano Rafael Reig reafirma su propuesta literaria rindiendo tributo a los géneros populares, particularmente a la picaresca, a través de su novela Para moririguales (2018). En esta, el camino recorrido por el protagonista suscribe varios de los elementos esenciales del género clásico de los Siglos de Oro, pero, a través de un movimiento paradójico propio de la posmodernidad, niega y reescribe otros, destacándose como móvil narrativo un regreso imposible a la infancia, entendida como única vía de redención del héroe. Se llevará a cabo de este modo una picaresca que tiene como punto de partida la última etapa del franquismo, una infancia de penurias en la Sagrada Familia y la orfandad por muerte y prisión de los padres del personaje principal a causa de una acción guerrillera. No obstante, los recuerdos de su primera juventud parecen dar luz de esperanza a una de las épocas más oscuras de la España contemporánea. Nos encontramos ante un nuevo pícaro, uno que procura el retorno a esa infancia de miseria, por considerarla la única etapa verdadera de su vida, su único mundo posible (a la vez que utópico), en términos de Lubomír Doležel.
\end{abstract}

Palabras clave: reescritura; picaresca; mito; mundos posibles.

"Y volver, volver, volver": picaresque rewriting and possible worlds in Para morir iguales by Rafael Reig

\begin{abstract}
Contravening the myth of the rogue studied by Claudio Guillén, the Asturian narrator Rafael Reig reasserts his literary project by paying tribute to popular genres, and particularly to the picaresque, through his novel Para moririguales (2018). In this work, the protagonist's journey conforms to several essential elements of the classical genre of the Siglos de Oro, whereas others are denied and rewritten in a paradoxical movement typical of postmodernity. Standing out among such rewritings is the narrative
\end{abstract}


motif of the impossible return to childhood, understood as the hero's only way to redemption. This results in a picaresque narrative that has as its starting point the final stage of Francoism, a childhood of hardships in the Holy Family, and orphanhood due to the death and imprisonment of the main character's parents following a guerilla operation. The memories of this early youth, however, seem to be a beacon of hope enlightening the darkest periods of contemporary Spain. We are facing a new kind of rogue, one who seeks to return to his childhood of misery, considering it to be the only true stage of his life, his only possible world (as well as a utopian world), in Lubomír Doležel's terms.

Keywords: rewriting; picaresque; myth; possible worlds.

\section{Reescribir para escribir}

Como si se tratara de los motivos o funciones bajtinianas, muchos de los elementos fundamentales en la construcción del pícaro que propone el narrador asturiano Rafael Reig pueden llegar a reconocerse en relación con el modelo clásico (s. XVI y XVII) sin mayor dificultad. Sin embargo, es posible advertir también una variante significativa en dicha construcción, pues, el antihéroe de la novela pretende, como una suerte de kairós utópico, el regreso a su infancia, claramente picaresca en su desgracia, orfandad y miseria: "llena de dolor y miedo, de violencia y vergüenza, pero en la que todo lo que ocurría era de verdad" (Reig, 2018: 141).

Sucede que en la novela la infancia es metabolizada y resemantizada con el paso del tiempo, acaso como un rechazo de la vida adulta, al punto de transformar las carencias de aquella etapa en oasis ucrónicos en los que el personaje central obtiene refugio a través de una anamnesis evidentemente reformada. De este modo, la otrora infeliz edad se convertirá nuevamente en el sueño y objetivo del protagonista. Este, al intentar el regreso al pasado comprobará, sin embargo, que dicho viaje es imposible y el causante de su postrero mal. Procurando el cobijo del héroe clásico, el personaje hallará, a diferencia de los relatos míticos tradicionales, el desencanto de la picaresca. Además, esa búsqueda de retorno hacia sus primeros años se verá agravada por otra forma de desencanto posmoderno que nos recuerda las palabras de Joseph Campbell (2001) respecto al viaje del héroe y su alejamiento del umbral protector que el hogar simboliza, una que en la novela está representada por el anhelado (y utópico) regreso:

Este es un sueño que acentúa el primer aspecto del guardián del umbral, o sea el protector. Es mejor no sacar al guardián de los límites establecidos. Y sin embargo, solo atravesando esos límites, provocando el otro aspecto de la misma fuerza, o sea el destructor, pasa el individuo, ya sea vivo o muerto, a una nueva zona de experiencia (93).

Esta imposibilidad de egresar de la zona de destrucción (autodestrucción en este caso) mantiene atrapado al personaje central de la novela en un malogrado eterno retorno a sus primeros años, sin poder acceder del todo a esa "nueva zona" de la que habla Campbell.

Para moririguales, en tanto que reescritura, es un tipo de transposición heterodiegética de muchas de las constantes del género, pero si consideramos las obras paradigmáticas de este, la coincidencia, aunque también la confrontación, más que a nivel architextual o hipertextual, ocurre en torno a la presencia mítica del pícaro, así como al itinerario fundamental de estas narraciones, guiadas por la lucha por la supervivencia en el territorio hostil de una infancia marcada por las necesidades (físicas y emocionales), un espacio en el que el protagonista manifiesta como principal interés 
el abandono radical de la pobreza: "A mí lo único que me interesaba entonces era ser muy rico" (Reig, 2018: 114). Pero en este caso, esas dificultades se actualizan desde el mundo canónico de la picaresca (lo que Doležel denomina protomundo) hacia unas coordenadas contemporáneas, cuyo punto de partida comienza con la Transición a la democracia, para llegar hasta nuestros días, consolidándose así la mencionada transposición reescritural.

La novela de Reig también altera con su reescritura algunos de los motivos tradicionales del personaje picaresco (transmotivación, según Genette). Lo que Michel Cavillac (1993) identificara como las tres conversiones del pícaro, ${ }^{1}$ orientadas estas: a la sana economía, a la ortodoxia religiosa y a la fina política, no serán prioridades para el personaje contemporáneo. Este nuevo pícaro, en su edad adulta, no pretende conformarse únicamente con la supervivencia, sino alcanzar la riqueza (aunque la obtenga de manera ilícita), ni le basta, en última instancia, la seguridad material más prosaica: "a finales de los noventa, teniendo ya mucho más que «coche y nevera», decidí hacerme rico de verdad" (2018: 76). Sin embargo, una vez obtenida esa riqueza, lo que el protagonista realmente busca a lo largo de toda la obra es recuperar la vida de amistad y amor verdaderos que cree haber dejado atrás en su niñez. Esta diversificación en los motivos será una distinción central en el perfil del pícaro reigiano.

\section{Más infancia, más paradoja}

Otra divergencia entre la picaresca clásica y la que tiene lugar en la novela se halla en el enfoque que de la infancia se hace y en el privilegio narrativo que a esta se le otorga. A diferencia de los hipotextos de los Siglos de Oro, en los que la niñez de los protagonistas suele tener un lugar sucinto y supeditado a la vida adulta (de la que, en todo caso, resulta un justificativo), en la novela de Reig la infancia es, no bien se la deja atrás, un destino al que regresar que ocupará buena parte del argumento. Posiblemente esto suceda, como lo plantea Cabo Aseguinolaza (2001) porque "acaso la infancia pueda entenderse como un concepto o un sentimiento moderno. Como una categoría, en suma, que no debe tomarse sin más como universal" (23). La infancia oficia en la obra de Reig como un topoi literario al que volver, y no como un lugar que hay que abandonar para que la vida comience. Esto "permite el paso hacia la reflexión sobre el lugar que el viejo tópico de las edades del hombre puede ocupar, por poner un caso, en la ideología estética de la modernidad" (Cabo Aseguinolaza, 2001: 23), y que puede extenderse sin problemas hasta la posmodernidad como preocupación vertebral en la construcción narrativa de Reig.

Uno de los leitmotiv de la obra del narrador español radica en la constante oposición a la figura tradicional del intelectual, creada, según este, a partir del despliegue literario de Francesco Petrarca, que hizo escuela en toda Europa, consolidándose con la llegada de la modernidad. Por ello, no es de extrañar que Para moririguales, como si de un antídoto se tratase, tenga a un personaje protagonista que sirve para plantear "la introducción, frente a la linealidad más rígida (la de la modernidad), de un principio regresivo; esto es, la presencia del pasado como elemento sustancial tanto del presente como, acaso de modo más relevante, del futuro" (Cabo Aseguinolaza, 2001: 46). Tal y como se expresó, la infancia será, en una novela posmoderna, una irracional pulsión, un paradójico objetivo a futuro. 
Un texto que puede negar a la vez que reafirmar a otro en una tradición expresa claramente la idea de paradoja que, según Linda Hutcheon (1995), es el rasgo distintivo de la posmodernidad. La reescritura existe en tanto proceso binario que, por una parte, confirma el protomundo canónico y algunas de sus leyes estructurales, y, por otra, lo niega, proyectándolo hacia el futuro o hacia su prehistoria. De este modo, se establece un diálogo con el presente, revisionando y revisando tal construcción. Ese gesto dual, en consonancia también con la noción de reescritura que propone Doležel, se aleja de la concepción tradicional de influencia, acercándose a la idea de doble irradiación que el crítico checo defiende, generando un sustento dialógico entre hipotexto e hipertexto. El propio Reig fundamenta esta noción en uno de sus textos más teóricos, Señales de humo:

Así pues, un escritor inventa una tradición, no la acepta ni la recibe, sino que la crea, porque el presente, como diría T. S. Eliot, también altera el pasado [...] la tradición literaria es un río cuyas aguas corren tanto hacia atrás como hacia adelante. Al leer a César Vallejo, se modifica nuestra lectura de Quevedo o de Villon; Poemas humanos es algo que también les sucede a los sonetos de Quevedo, como a los de Garcilaso les sucede la poesía de Neruda, o como el Lazarillo y el Quijote le suceden a quien escribe hoy una novela (2016: 267).

¿Autoprofético? En términos de creación literaria, este texto anticipa el caso planteado dos años después en Para morir iguales, donde el personaje replicará, de manera transpositiva, muchos de los elementos constitutivos de la picaresca desde 1554 en adelante, aunque expandiéndolos más allá del escapismo o la urgencia de estabilidad material y del deseo constante de inserción social, arrojándose hacia su única y utópica pretensión, el retorno a una infancia que será concebida, a pesar de sus carencias, como la única etapa verdadera y feliz: "Puede que se haya avanzado mucho, pero a nosotros una infancia desprotegida nos parecía el mejor regalo que nos podían hacer" (Reig, 2018: 70).

Un hecho no menor que menciona Hutcheon en su texto es la autoconciencia del proceso reescritural. En Para morir iguales, existen varios momentos en los que esto se evidencia. Incluso algunos cuya presencia en el texto, aunque ínfima a nivel cuantitativo, resulta significativa en relación a la reescritura. Aquí, otra característica de la reescritura reigiana: sin la necesidad de una transposición completa de secuencias reconocibles, a través de breves pero contundentes fragmentos intertextuales, el lector podrá asociar el texto que está leyendo con sus fuentes o protomundos, tendiendo sin dificultad un puente genérico. Para estos casos, propongo la noción de epifanía intertextual, como un momento en que, a través de un intertexto concreto, se establece un vínculo directo con todo un universo narrativo del que dicha cita es tanto muestra como metonimia, y no mera referencia anecdótica y circunstancial, sino un elemento central en el desarrollo de la trama novelesca. Esto se aprecia en la obra cuando, en claro guiño al Lazarillo, una de las monjas de la Sagrada Familia da consejo al joven protagonista (también huérfano) justo antes de su emancipación: “-Tú arrímate siempre a los buenos, Pedrito, y encomiéndate a la Santísima" (Reig, 2018: 47). En el acto mismo de reescritura el autor logra resemantizar el protomundo, rejuveneciéndolo, pero, a su vez, desafiándolo, pues pone a prueba su vigencia como entidad clásica. Los buenos serán, irónicamente, los mismos de la picaresca áurea, aquellos que puedan dar lugar a la subsistencia del personaje principal. Sin embargo, en la novela de Reig no resulta suficiente con sobrevivir, como hemos dicho, ni siquiera con la riqueza material, por lo que el personaje se embarcará en una empresa imposible buscando otro tipo de sustento, acaso existencial, fundado en la fidelidad del amor y la amistad infantiles. Doležel (1999) deja en claro el doble movimiento reescritural que tiene cabida en textos como este, al afirmar que la teoría crítica posmoderna "cuestiona y corrige el 'canon' literario establecido y heredado" (287). 


\section{No solo clásicos, no solo pícaros}

Según lo dicho, con los movimientos de transposición la historia fuente no puede sino abrirse en su horizonte hermenéutico, según advierte Hutcheon: "among the many things that postmodern intertextuality challenges are both closure and single, centralized meaning" (1995: 127). Esto no significa de ningún modo que los textos clásicos se encuentren cerrados a un significado único, pero claramente la condición posmoderna es la que hace imposible una simplificación interpretativa unidireccional cuando se trata de una reescritura. Ni siquiera la picaresca que nos ocupa es el único género que Reig utiliza como fuente $y$, de hecho, su hibridación architextual con el policial, la novela de aventuras o el bildungsroman son también vertebrales en la construcción e influencia que recibe el pícaro reigiano: "En la casa también había libros y [...] siempre me acompañaba un nuevo amigo: Tom Sawyer, Pip, Gabriel Araceli, Miguel Strogoff o Pedrito de Andía" (Reig, 2018: 59). El protagonista de la novela, Pedrito Ochoa, como los de la novela de formación, pretende construir su vida, pero, a diferencia de aquellos, para sobrevivir, termina destruyéndola y deformándose hasta el paroxismo. Evidentemente, el ejemplo puede extenderse no solo al plano de las referencias intertextuales, sino a todas las prácticas transtextuales que están vinculadas al fenómeno reescritural: "en la reescritura posmoderna [...] la intertextualidad es solo un factor auxiliar de un vínculo histórico y semántico más profundo, la transducción del mundo ficcional" (Doležel, 1999: 291).

Según lo planteaba Linda Hutcheon, uno de los rasgos esenciales de la posmodernidad está dado por el vínculo entre la reescritura y la creación y recreación de mundos ficcionales, pues es característico de los textos posmodernos (sin que sea exclusiva de estos) su densidad (acumulación del archivo) y reproductividad. Ese tejido de naturaleza literaria, además de contener el pasado, desarrolla la idea de los mundos posibles, basada "en la contingencia de los mundos" con la que Doležel da cierre a su Heterocósmica:

cualquier mundo o cualquier entidad en el mundo podría haber sido diferente de lo que es. Las reescrituras posmodernas crecen en este fértil suelo semántico [...] La complejidad del significado de lo reescrito y su desafío a la interpretación semántica se debe, precisamente, al hecho de que no sólo refiere a su propio mundo ficcional sino también, de maneras y en grados diversos, a su fuente, el protomundo (1999: 311).

Esta evocación supone una convalidación de modos expresivos precedentes, así como una oposición a estos al ofrecer una nueva variante. Parece claro que los personajes de Para moririguales responden a motivos literarios similares a los de la picaresca clásica, pero requieren también una transposición de las coordenadas hipotextuales de aquellos. La virtud transposicional podría ser una explicación a la perennidad de los textos clásicos, propiciada por su capacidad adaptativa, algo así como su potencial proteico, su habilidad para transformarse sin perder sus elementos vertebrales. Como veremos, la refundación del mito del pícaro es esencial en la funcionalidad de esta reescritura, creando así un perfil propio, contemporáneo, reigiano. De este modo, queda expuesta la paradoja reescritural existente entre la picaresca como novela fundacional de la literatura española, y los aspectos posmodernos que su hipertexto ofrece, los cuales posibilitan esa forma de transposición previamente aludida. 


\section{Un pícaro en la Transición}

Entendida como una tendencia natural de los procesos de reescritura, el vínculo con lo clásico, según se ha visto, es proverbial. El protomundo picaresco, originado en el primer Siglo de Oro, forma parte del periodo clásico por excelencia de las letras españolas y su reescritura también es la de toda una tradición. ${ }^{3}$ Sin embargo, la transposición reescritural que tiene lugar con la obra de Reig, al incurrir en un cambio de coordenadas espacio temporales, posibilita su enfoque posmoderno, cuyo marco narrativo, que llega hasta nuestros días, comienza con la muerte del dictador Francisco Franco: "Huérfanos del Caudillo, fuimos adoptados en el acto por la democracia" (2018: 28).

En relación con el contexto sociocultural de la España de la Transición, la visión de Teresa Vilarós (2018) resulta más que ilustrativa, ya que, por un lado nos recuerda que la apertura hacia la democracia y la posmodernidad compartieron una misma entidad en el contexto español: "no hay que olvidar que en España la posmodernidad coincide y se hace posible con la muerte de Francisco Franco" (59). Pero, por otra parte, también nos señala que en el germen de esas ideas un día revolucionarias e innovadoras ya se hallaba su ulterior fracaso, que es el del protagonista de la novela (heredado de sus padres guerrilleros y presos políticos), y también el de toda una generación: "En España, a finales de los años sesenta y principio de los setenta, la inviabilidad de la utopía de la izquierda española de la época franquista está ya explicitada" (63). Este hecho justifica en parte y se complementa con la desideologización del pícaro reigiano, quien pretende, más que la justicia social del estado de derecho, el ascenso de clase, el dinero y el poder que este otorga y que ha visto como estandarte de las aristocráticas familias de sus amigos, llegando a renegar de la suya propia: "Así fue como me di cuenta de la insignificancia de mis abuelos y de las reducidas dimensiones de mi Gran Porvenir, y en ese mismo instante me propuse a toda costa ser tan asquerosamente rico como los Carlones" (73-74).

El contexto posmoderno, y particularmente el que se genera a partir de la Transición, acorde a los planteamientos de Ángeles Encinar (1990), es el que intensifica la desaparición del héroe en la novela española, propiciado por "la incoherencia de la vida moderna, que con frecuencia obliga a mantener diferentes 'roles' (y) produce una desintegración de la personalidad" que bien se identifica con la del ser escindido entre dos mundos que representa Pedro Ochoa, protagonista. Sin embargo, así como la autora plantea la desaparición del héroe en consonancia con la del personaje (en el sentido tradicional de este término), ${ }^{4}$ y reconoce "un vacío de creencias y la importancia concedida al momento presente" (182) como causas de esa evanescencia heroica, vale la pena señalar que la obra de Reig rompe con esta regla. El autor, al tomar como personaje modélico al pícaro (centrado en la proyección hacia su prosperidad futura, antiheroico por antonomasia), pero imprimirle, simultáneamente, un deseo utópico (el regreso a la infancia), confirma una vez más la paradoja reescritural de la que hablaba Hutcheon y su evidente bidireccionalidad, que es también la del espíritu del personaje.

\footnotetext{
3 Un punto frecuente en las obras de Reig y, particularmente en sus dos tomos del Manual de literatura para caníbales (Señales de humo y La cadena trófica), es la reivindicación de una tradición de estirpe cervantina, con gran protagonismo del elemento lúdico y del humor como pilares ante otro modo de entender la res literaria que sería el representado por la figura del intelectual, diana principal de las críticas del autor.

4 Ángeles Encinar sostiene en su estudio que son estas dos tendencias las que marcan la evolución de la novela española desde "principios de 1970 " en que "ya se puede observar un giro espectacular en el trato concedido a los personajes, llegando a un extremo en el que resulta difícil hablar de ellos como tales", arguyendo que "las intenciones retóricas se han impuesto y son expresadas mediante voces o entes abstractos que parecen sombras indefinidas del antiguo protagonista" (1990: 13).
} 
La novela de Reig hace referencia a una doble transformación del país a medida que se transforman, a su vez, los personajes, desde esperanzados demócratas: "la voz de Pardeza hablando de la democracia y del viento de la libertad, que, según dijo, soplaba con fuerza para llevarnos muy lejos" (Reig, 2018: 71), hasta agentes de cambio en decadencia: "según Pardeza, el país se hallaba al borde de un precipicio y había una guerra subrepticia, con pistoleros a sueldo, terroristas vascos, guerrilleros de Cristo Rey y violencia gratuita, aunque no desinteresada" (100). Así como la obra se debate entre dos mundos posibles que representan claramente dos momentos en la historia social de España, ${ }^{5}$ también el personaje tendrá una clara división, como lo anticipa sutilmente la cita anterior, marcada en este caso por la inocencia de la niñez en contraste con la picardía que desarrollará durante el transcurso de la historia, pervirtiéndose desde la temprana adolescencia, paradójicamente, a medida que la dictadura queda atrás y la democracia progresa. Representa esto una clara dualidad en la traslación del protomundo de la picaresca al contexto de la Transición, el que también, en palabras de Vilarón (2018), se ha degradado, perdiendo su rumbo en productos culturales como la Movida madrileña, tan creativa como autodestructiva: "La expansión extática de la movida -criada en alcohol, hachís, 'poppers', cocaína y caballo- tiene el sentido de conjurar el efecto monumental de la resaca producida por la pérdida del contenido utópico de la superestructura cultural de resistencia a la dictadura" (69). El personaje central de la novela buscará también anestesiarse ante un contexto adverso, pero será su regresiva utopía (otra forma de narcótico) la que no le permita aceptar el presente como forma de transición, sino como padecimiento continuo.

\section{Picaresca y mito}

Pedro Javier Pardo en su ensayo Don Quijote cabalga de nuevo. Reescrituras del mito quijotesco, en consonancia con la paradoja posmoderna que planteaba Hutcheon, elabora un juicio que sintetiza parte del movimiento reescritural que tiene lugar en casos como el de Reig, cuando la transposición de una obra clásica a "un mundo contemporáneo suele utilizarse para oír lo que la obra tiene que decir sobre el mismo, por tanto para aproximar o perpetuar su sentido" (Pardo, 2013: 186). Ese es el objeto primordial de esta forma de reescritura propuesta por Reig, de ese modo funciona, instalando los componentes clásicos en un entorno contemporáneo y poniendo a prueba su actualidad, indagando en su vigencia, en su capacidad de continuar ese diálogo entre textualidades. Sin embargo, en Para morir iguales no nos hallamos únicamente ante el intento de perpetuar la esencia de obras como el Lazarillo o el Guzmán, sino de alcanzar una amplitud reescritural superior, incluso más allá de obras puntuales, en el terreno de la claseidad de la que hablaba Genette, de manera multigenérica, con la presencia fundamental, incluso, de las novelas de formación o de aventuras, según se ha dicho. Lo que el novelista consigue con estas prácticas es revitalizar el diálogo con la tradición a través del vínculo que, a nivel architextual, establece con la picaresca (en primera instancia), y ampliar su propósito hacia el terreno de la literatura popular, creando un nuevo tipo de pícaro con su propio trayecto mítico.

La reescritura de los paradigmas esenciales de un protomundo como el de la picaresca es, por tanto, un medio para un fin superior, reivindicativo. Se pretende reubicar el eje creativo en una línea que Reig plantea como imprescindible, y así lograr la reconexión con las bases de su tradición literaria, pero, como es propio

5 Por un lado, el mencionado final del franquismo y el comienzo de la Transición, que tiene lugar al inicio de la novela, durante la niñez del protagonista en el internado de la Safa, y por otro, la España de la burbuja inmobiliaria y el crecimiento económico desmedido que dará lugar a la continuidad picaresca del personaje en la vida adulta, enriqueciéndose ilícitamente y de manera inescrupulosa, pasando de la lucha por la supervivencia a una codicia inmoral como respuesta radical ante el miedo a retornar a la pobreza. 
de la posmodernidad, su carácter heteróclito hace difícil una clasificación pura, perteneciente a un único género, por lo que este propósito tampoco se ajusta a esta novela. ${ }^{6}$

Como se ha propuesto hasta el momento, no solo la hipertextualidad puede considerarse como fundamental al momento de llegar a la reescritura, sino que los architextos e intertextos también pueden representar un elemento igualmente valioso para tal proceso. También existen unidades menores que por su presencia constante pueden establecer otro tipo de vínculo a nivel del estudio de la reescritura. Para el caso del mito sucede que, de manera general, contiene en su estructura narrativa un itinerario con diversas secuencias, cuyo protagonista, el héroe, suele desarrollar hasta alcanzar su objetivo. Para el mito del pícaro, el caso puede ser más que equiparable. ${ }^{7}$

Luis Martínez Falero señala la importancia que tiene la aparición del mito "periódicamente en la literatura, como actante de tipo comparativo (mediante la amplificación o la reinterpretación de un mitema ${ }^{8}$ característico del arquetipo original)" (2013: 488). Este tipo de recurrencias debe considerarse como un elemento fundamental de la reescritura en cuestión, sobre todo si mantenemos la convicción planteada al comienzo, en relación con la importancia architextual y las pautas que el género marca y el lector espera. Danièle Chauvin sostiene que "la intertextualidad es incluso en muchos casos uno de los procesos fundamentales para la edificación, es decir, para la perennidad del mito" (2005: 175). Ejemplo de esto es la ya mentada cita (única del protomundo picaresco) en la que el protagonista recibe el consejo de "arrimarse a los buenos", y que también, como en el texto clásico, tiene lugar en el comienzo del duelo emancipatorio. Por cierto, estas secuencias, ya fueren explícitamente intertextuales, hipertextuales, o aún más vastas, originadas a través de la architextualidad, pueden considerarse de igual modo como aspectos básicos en el proceso de reescritura que plantea Reig. En esta línea, el mito, compuesto por esas constantes, puede ser entendido como una marca tanto hipertextual, con un héroe que, al igual que en historias precedentes, tuvo que enfrentarse a un cierto número de obstáculos, como architextual, cuando la vinculación con una serie de elementos constitutivos del relato pasa a ser reconocible como marca de género: "ausencia de padres, familia, contexto social adverso" o los "orígenes bajos e infamantes" (Pardo, 2002: 149-150).

Al referirnos al mito del pícaro debemos establecer ciertos parámetros conceptuales para su tratamiento. Este caso no representa, sensu stricto, un arquetipo, ni se corresponde con la figura de personajes heroicos pertenecientes a una edad dorada, más bien se construye en las antípodas de aquellos, así como de los valores absolutos que representan. Según Claudio Guillén, en relación con las figuras preexistentes a nivel narrativo, este sostiene que tiene lugar: "a combination in the memory of the artist of certain already existing prototypes", y reconoce, (como lo hace Reig de manera explícita o implícita) que las bases de dichos modelos están, primero en el Lazarillo de Tormes, que representa "the primitive form" y luego en el Guzmán de Alfarache, que oficiará como modelo a seguir por ser "the main target of imitation for many decades" (1973: 73). Sin embargo, la construcción reigiana, determinada por el contexto de la Transición, es vista por el autor como el inicio de una decadencia, y no de una redención, lo que coincide con la distinción de

6 El protagonista, como se refirió al inicio del trabajo, se llama Pedro Ochoa, y él mismo se encarga de compararse con personajes no solo de la picaresca, sino también de la novela de formación, el bildungsroman, con el que, amén de las diferencias formativas del héroe, la picaresca puede tener sus puntos en común, más en la búsqueda de una identidad adulta que en el resultado de tal recorrido.

7 Resulta interesante advertir que esas secuencias pueden relacionarse con varios conceptos análogos en tanto que unidades constantes en el camino del héroe: los mitologemas de Karl Kerény, los mitemas de Lévi-Strauss, e incluso las funciones de Propp, aplicadas a los cuentos tradicionales, por citar algunos ejemplos.

8 Entiéndase el término según lo plantea Claude Lévi-Strauss en su Anthropologie structurale como cada una de las frases mínimas particulares en que se descompone el relato de un mito (1974: 235-265). 
Juan Villegas (1973), quien recuerda que "los mismos mitos recreados en diferentes momentos históricos son portadores de mensajes y contenidos dependientes de la Weltanschauung correspondiente" (16).

Cercano entonces a la figura antiheroica, el pícaro puede definirse más claramente por su antagonismo con algunos de los mitos fundacionales de la cultura occidental, como es el caso del mito adánico. Pardo propone en su estudio sobre el mito del pícaro una definición por oposición con el mito del primer hombre. A diferencia de este, que en su dimensión colectiva (de carácter edénico) no aspira sino a la refundación de un Paraíso perdido, y en su dimensión individual (adánica) se siente el receptáculo del destino manifiesto del progreso y el esfuerzo personales (que se erigen como paradigmas), el pícaro tiene, en cambio, como guía, un repertorio de rasgos lejanos a toda pulsión heroica (Pardo 2002: 148-149). El personaje de Pedro Ochoa en Para moririguales, a pesar de lograr ese éxito económico planteado desde sus primeros años en la Safa, terminará derrotado en su construcción personal, a pesar de que "ese fracaso puede estar disfrazado de éxito, bien sea material, como en el Lazarillo, bien espiritual, como en el Guzmán. De manera tal que el éxito como absoluto, a diferencia del mito adánico, al pícaro le será siempre esquivo" (Pardo, 2002: 150-151). Evidentemente, el personaje de Reig atraviesa un proceso de deformación, ya que, opuesto a lo que pasa con el bildungsroman, el personaje se corrompe, acercándose al mundo del crimen y de la estafa: "así que fue él quien me sugirió el plan más sencillo. Un robo seguido de un atropello que la mantuvieran hospitalizada quizá durante varios días" (2018: 231). Esa degradación moral alcanza su paroxismo en la mencionada necesidad de enriquecerse a cualquier precio, concebida como una fatalidad, como lo manifiesta el personaje al declarar que "ya era demasiado tarde para volver a ser pobre" (2018: 232). Sin embargo, a diferencia del pícaro de los Siglos de Oro, este nuevo pícaro, posmoderno y paradójico, así como expone sus antivalores, también ostenta rasgos plausibles, como su fidelidad a la figura del amigo de la infancia, Jesús Escurín, quien "se convirtió - para el resto de su vida- en el más fiel amigo [...] a veces me llamaba "hermanito"' (93); o su amor por Mercedes Ponzano: "el rostro de Mercedes era para mí una de las pocas cosas por las que la vida merecía la pena" (233-234). Según Hugo Bauzá, las penurias que atraviesa el héroe clásico traen aparejado un número de transformaciones redentoras que son parte de su evolución como arquetipo, por tanto, la "purificación, la transfiguración y una suerte de apoteosis se da en las naturalezas heroicas por medio del sufrimiento y de las lágrimas [...] En ellos (en los cambios del héroe) se asiste a una suerte de metánoia, es decir, un cambio de sentimientos, no forzado, sino natural y autocomplaciente" (Bauzá, 2007: 132-132). Sin embargo, para el pícaro de Reig, ni el donum lacrimarum ni los sufrimientos que lo provocan serán redentores ni poéticos, sino un reflejo de su decadencia: "La primera noche en el chabolo estuve a punto de llorar, pero me aguanté las ganas hasta que me quedé dormido" (225).

\section{Tan solo utopía}

Según los rasgos tradicionales del pícaro, es posible caracterizarlo como un ser escindido que no pertenece concretamente a ningún lugar, para quien la felicidad es el equivalente a haber medrado, entre el temor al retroceso en su prosperidad y la resignación a soportar "el sí sé qué y el no sé qué" de las infamantes voces populares, como ocurría con el narrador del Lazarillo. Guillén sostiene que el pícaro clásico puede definirse como un half-outsider, cuya existencia oscila "between vagabondage and delinquency", un ser nunca inmerso completamente en ninguna de las esferas sociales (1973: 80). Esta noción puede juzgarse como medular y permanente, aunque pasible de matices. El personaje de Reig acentuará una de esas dos características para suprimir la otra, pues, a través, no ya del simple pillaje, sino de la estafa, e incluso 
como autor intelectual de un crimen, sorteará la vida errática del pícaro en términos físicos, y alcanzará la riqueza, mas sin poder obtener nunca un verdadero equilibrio de sus emociones, llevando consigo la paradójica nostalgia de su infancia.

Sabemos que los protagonistas de la picaresca nunca alcanzan a construir un retrato literario inmaculado, más bien lo contrario. Cuando en el mejor de los casos obtienen éxito económico (siempre relativo y acorde a sus posibilidades), espiritualmente han fracasado, como puede ser el caso del Lazarillo; cuando logran alguna forma de trascendencia a ese nivel, las necesidades no dejan de ser una asechanza constante, como sucede con el Guzmán. En su comparación entre el mito adánico y el picaresco, Pardo apunta con precisión que este, a diferencia de aquel, se desarrolla a partir de "una visión descarnada y degradada de la naturaleza humana y la sociedad, la negación de la utopía" (2002: 150). Esa búsqueda de lo imposible en relación con paraíso perdido de la infancia se manifiesta como una pulsión pendular entre el determinismo pesimista con que el narrador se refiere a su vida y su futuro -"ya era demasiado tarde, nunca conseguiríamos ser atractivos" (Reig, 2018: 24)-y la redención utópica que le supondrían la amistad o el amor: "la Mercedes real no existía; quería el recuerdo de mí mismo enamorado de ella en el Hogar" (201-202). Ambas variables se encuentran ausentes en el ideario picaresco clásico, determinado por necesidades de índole más inmediata. El mito del pícaro, en tanto que negación de la utopia, entra en contradicción, pues, con el inverosímil regreso del personaje a su infancia, expresando así la paradoja reescritural posmoderna de la que hablamos al comienzo, ya que, por un lado logra metabolizar los elementos clásicos, pero, por otro, niega parcialmente este relato mítico, al exhibir ese carácter nostálgico por una etapa de la vida que el arquetípico personaje desea abandonar lo más prontamente posible, pues, resulta ser epítome de sus carencias. La infancia del Pedro Ochoa de Reig es reconstruida como un relato muy ligado al mito, pero no necesariamente con exclusividad al que describe Guillén. El planteado por Reig será un mito propio, entre la búsqueda del pícaro clásico y el desencanto posmoderno.

Cabo Aseguinolaza nos recuerda que la infancia "se asocia estrechamente a un trasfondo ideológico de contornos próximos al mito" (2001: 32). En Para moririguales la única esperanza del héroe es absurda en sí propia, ya que pretende sostenerse a través del viaje al pasado, una suerte de ucronía hacia ese mundo adánico por reencontrar del que hablaba Pardo. ${ }^{10}$ La división entre el yo interno y el externo (social) del personaje reigiano, se puede emparentar con la que señala Guillén como constitutiva del mito picaresco, presente entre su "inner man" y su "outer man" (1973: 81) pero, a su vez, trasciende estas categorías. En el caso de la novela, desde lo ideológico el personaje se juzga a sí mismo como perteneciente al grupo de los que habían "perdido ya toda esperanza de ser atractivos" (2018: 13) y plantea tal condición como inalcanzable e inherente a otra clase de personas, como sus compañeros del colegio privado, hijos de los poderosos, "chicos a los que les quedaba bien el uniforme y que no se sentían de antemano avergonzados o culpables" (2018: 64). Esta brecha sociológica que la novela exhibe alcanza otra resonancia en tanto que reescritura de la picaresca, no necesariamente como una distinción entre los desposeídos y los dueños del capital (en sentido materialista-histórico), sino entre dos destinos humanos cuya comunión resulta imposible. Esto permite, por

\footnotetext{
9 El personaje de la novela utiliza el término "atractivo" como signo de status y prestigio social que, en su ausencia, funciona como un estigma negativo y en la novela como un leitmotiv que hará las veces de ritornello: "Eso fue lo primero que descubrí [...] años después de la visita al teatro que había sido nuestro colegio: que las dos Españas separaban a los atractivos de quienes no lo somos" (Reig, 2018: 27).

10 El personaje, hacia el final de la novela, visitará los antiguos edificios de la Sagrada Familia, el internado de su infancia, encontrándose allí con su amigo Jesús, y con su amor imposible, Mercedes (los nombres parecen también potenciar el significado), intentando recuperar vanamente el tiempo perdido: “No había cadena puesta y, desde dentro, fue Mercedes quien abrió el portón de hierro que me invitó a volver a la única vida real que conocemos: la infancia” (Reig, 2018: 239).
} 
reticencia, comprender muchas de las características de este pícaro en particular y el carácter utópico de su búsqueda, dotándolo, a pesar de su vileza, de un idealismo particular en pleno desencanto de la Transición:

Aquella plaza cuadrada era la mayor concentración de personas atractivas que hasta entonces había visto en un espacio tan reducido. Chicos y chicas, todos eran delgados, y no solo les sentaba bien la ropa, sino que con ella -y mediante el peinado, la forma de andar y hablar, y hasta los abalorios- conseguían expresar una visión del mundo, su propia creatividad, su fe en la democracia y otros muchos buenos sentimientos (Reig, 2018: 181-182).

Queda claro entonces que tal condición de "persona atractiva" se plantea como irreversible y determinante, más allá de la prosperidad económica que el protagonista logra alcanzar en el transcurso de la historia, vinculada al delito, la usura y la perversión moral. Sucede, pues, que el pícaro estará ligado indefectiblemente a un futuro delincuencial, "en el peor de los casos", o a convertirse en "un profesional del engaño en el mejor", ya fuere "por los pecados de los padres", como "por los orígenes bajos e infamantes que anuncian un destino degradado" (Pardo, 2002: 150). En el caso de Pedro Ochoa, su pasado lo vincula a una madre asesinada por sedición y robo y a un padre preso por idéntica razón: "mi madre, la comunista, la pobrecita Elena, se la había tragado el agua (¡muerta a balazos como una mexicana!); y mi padre, Enrique Ochoa, el atracador de bancos, había sido apresado" (Reig, 2018: 79). El pícaro, entonces, afectado por el determinismo de su clase, su familia y condición, se define por su conciencia de la adversidad, sabiéndose siempre fuera, un half-outsider ad hoc, según lo planteado anteriormente. Esta suerte de nefanda herencia, por consiguiente, "junto con una prematura orfandad o abandono del hogar familiar sitúa al pícaro desde el principio en esa posición de soledad cósmica" (Pardo, 2002: 151). Para el caso de Pedro Ochoa, narrador protagonista de la novela, el origen personal le confiere una doble mácula y, por ello, una conciencia dual de exclusión y marginalidad: a) "en el colegio éramos tantos los que teníamos padres entre rejas" (Reig, 2018: 21); b) "Nosotros, los de la Safa, habíamos perdido ya toda esperanza de ser atractivos" (113). Esa vacilación constante entre dos mundos es la que, según Guillén, representa la esencia de la picaresca y del héroe moderno:

This profound vision of the hero [...] perhaps its most substantial contribution to the thematics of the modern novel (its shattering of the unity of "dual man", its concentration on the dreams and the thoughts of fictional beings, its unrealistic saturation with inwardness) (1973: 89).

Marie-Catherine Huet-Brichard sostiene que el mito literario tiene como particularidad la capacidad de reinventarse (reescribirse) de manera progresiva a lo largo de la historia, al punto tal que llega a representar la suma de todas sus versiones anteriores, que acabarán también por configurarlo (2008: 42-44). El ya citado Villegas (1973), en consonancia con este planteo proteico en relación con la figura mítica afirma: "En la novela moderna, dicho de modo general el esquema inicial se repite, aunque disminuye la importancia del viaje como desplazamiento físico y se le sustituye por experiencias internas o intelectuales" (15), lo que claramente se vincula con la reclusión inicial del protagonista en el orfanato de la Safa y su dilema interno, ya en la adultez, entre regresivo y utópico. Mediante este proceso transformativo es que la reescritura tiene lugar, ganando terreno y perpetuándose, a veces por vía imitativa o, como en el caso de la obra de Reig, a través de la transposición de un protomundo y el conjunto de paradigmas que lleva consigo. Es lícito asociar ese protomundo con el que Yeleazar Meletinski identifica como el habitado por los "protoantepasados" (2001: 169-184), y concluir que tanto Lazarillo, Guzmán, Pablos, y demás pícaros clásicos, son parte fundamental del abolengo literario del personaje reigiano, y dan cuenta del 
vínculo hipertextual, así como del género picaresco en tanto que fuente, exponiendo su relación indisoluble con el universo architextual. Dicho esto, cabe agregar que la reescritura que tiene lugar en Para morir iguales, además de reforzar el vínculo con un tipo de personaje (el pícaro), un modo de narrar (el de la falsa autobiografía a la usanza de la primera picaresca), y un género, lo que consigue es defender un modo de entender la literatura, el modo en el que el autor de la novela concibe que debe discurrir la literatura, alineada con la reivindicación de los géneros populares, los cuales, como se ha expuesto al comienzo, representan para aquél la única forma de tradición auténtica de la literatura española. ${ }^{11}$

A modo de conclusión, luego de haber analizado los pormenores reescriturales de la novela Reig, no es aventurado afirmar que una de sus principales contribuciones radica en ofrecer una reevaluación de la infancia como patria literaria, uniendo al grupo de personajes de la picaresca el nombre de Pedro Ochoa. Esta idea, mantenida hasta el final de la novela, funciona como leitmotiv, y puede apreciarse desde el comienzo como una declaración de principios: "Ahora me doy cuenta: para cualquiera con vida, lo único irremediable -y lo único verdadero- es la infancia" (Reig, 2018: 19). ${ }^{12} \mathrm{Sin}$ embargo, esa conciencia no será suficiente para redimir al personaje del sufrimiento padecido, sino que, en oposición a lo que acontece con los héroes clásicos, como postulaba Bauzá, las penas, en lugar de representar una expiación, en el caso del pícaro contemporáneo, terminan hundiéndolo aún más en la ignominia. Según lo planteado, a través de la reescritura picaresca se articula la idea de la infancia como fundamento para la construcción del personaje protagonista. No obstante, a diferencia de la picaresca clásica en la que este periodo equivale, "aunque sobresaltado, (a) un sueño del que despertará de manera violenta" (Cabo Aseguinolaza, 2001: 15), en el caso del pícaro reigiano, ese despertar no ocurre nunca, ya que el sueño funciona como móvil utópico de la trama narrativa, en la que el personaje refleja en simultáneo, su nostalgia por la infancia, y el fracaso de esta etapa como germen de una felicidad futura.

11 En Señales de humo Reig escribe: "Cada escritor (y cada generación literaria) lee la tradición y la utiliza de manera diferente, la crea, como el autor del Lazarillo seleccionó entre los materiales disponibles [...] y así inventó su propia tradición; y la leyó de una forma tan nueva que le permitió inventar la novela moderna" (2016: 204). Y más adelante: “Desde el mester de clerecía al cine de Hollywood hay una línea recta [...] Lazarillo, Cervantes, Lope de Vega son otra línea recta: esfuerzos por volver a la tradición suprimida de la cultura popular" (268-269).

12 El tema está presente de manera constante en muchas de sus obras. En Señales de humo (2016) el protagonista también afirmará: "Cumplir en la edad adulta un deseo de la infancia es por tanto la única aunque escasa forma de felicidad a nuestro alcance” (Reig, 2016: 203). En Autobiografía de Marilyn Monroe se lee: “Los niños tienen que sentir cariño a su alrededor. De lo contrario, nunca podrán ser felices porque a quienes les ha faltado amor incondicional en la infancia les faltará siempre la capacidad para sentir el amor de los demás, para darse cuenta de que es real, con la misma realidad que posee un día de sol o como sentimos el viento en la cara" (Reig, 2019: 20). 


\section{Bibliografía}

》 Bauzá, H. (2007). El mito del héroe. Morfología y semántica de la figura heroica. Buenos Aires: FCE, 123-132.

"Cabo Aseguinolaza, F. (2001). Infancia y modernidad literaria. Madrid: Biblioteca Nueva.

»Campbell, J. (2001). El héroe de las mil caras. Psicoanálisis del mito. México: FCE.

"Cavillac, M. (1993). "Les trois conversions de Guzmán de Alfarache (Regard sur la critique récente”). Bulletin Hispanique, 1, 149-201.

»Chauvin, D. et al (2005). Questions de mythocritique. Paris: Editions Imago.

»Doležel, L. (1999). Heterocósmica. Ficción y mundos posibles. Madrid: Arco Libro.

»Encinar Félix, Á. (1990). Novela española actual: La desaparición del héroe. Madrid: Pliegos.

» Genette, G. (1989). Palimpsestos. La literatura en segundo grado. Madrid: Taurus.

" Guillén, C. (1971). "Toward a Definition of the Picaresque”. En: Literature as System: Essays toward the Theory of Literary History. Princeton: Princeton University Press, 71-106.

》 Huet-Brichard, M. (2008). Littérature et mythe. Paris: Hachette.

» Hutcheon, L. (1995). A Poetics of Posmodernism. History, Theory, Fiction. New York: Routledge.

" Martínez Falero, L. (2013). "Literatura y mito: desmitificación, intertextualidad, reescritura”. Signa: Revista de la Asociación Española de Semiótica 22, 481-496.

» Meletinski, Y. (2001). El mito. Madrid: Akal.

"Pardo García, P. (2018). “De la transescritura a la transmedialidad: poética de la ficción transmedial”. En: Gil González, A. y Pardo García, P. (eds.), Adaptación 2.o: estudios comparados sobre intermedialidad: “In honorem" José Antonio Pérez Bowie. France: Orbis Tertius, 41-92.

"Pardo García, P. (2013). “Don Quijote cabalga de nuevo: reescrituras filmicas del mito quijotesco". En: La noche se mueve: la adaptación en el cine español del tardofranquismo. Ed. José Antonio Pérez Bowie. Madrid: Los Libros de Catarata, 181-227.

»Pardo García, P. (2002). "El pícaro en el nuevo mundo: Reescrituras del mito adánico en la novela picaresca". En: Alvar, C. (ed.), El mito, los mitos. Madrid: Ediciones Caballo Griego para la Poesía, 147-159.

» Reig, R. (2019). Autobiografía de Marilyn Monroe. Barcelona: Tusquets.

"Reig, R. (2016). La cadena trófica. Manual de literatura para caníbales II. Barcelona: Tusquets.

» Reig, P. (2018). Para morir iguales. Barcelona: Tusquets.

» Reig, P. (2016). Señales de humo. Manual de literatura para caníbales I. Barcelona: Tusquets.

"Vilarós, T. M. (2018). El mono del desencanto Una crítica cultural de la Transición española (1976-1993). Madrid. Siglo XXI de España Editores. 
»Villegas, J. (1973). La estructura mítica del héroe en la novela del siglo XX. Barcelona: Planeta. 